\title{
Hydro-abrasive wear reduction of irrigation pumping units
}

\author{
Nazir Ikramov ${ }^{1 *}$, Takhir Majidov ${ }^{1}$, Makhmudjon Mamajonov ${ }^{2}$, and Olim Chulponov ${ }^{3}$ \\ ${ }^{1}$ Tashkent Institute of Irrigation and Agricultural Mechanization Engineers, Tashkent, Uzbekistan \\ ${ }^{2}$ Andijan Institute of Agriculture and Agrotechnology, Andijan, Uzbekistan \\ ${ }^{3}$ Namangan Institute of Civil Engineering, Namangan, Uzbekistan
}

\begin{abstract}
Uzbekistan is one of few countries in the world where more than $50 \%$ of the irrigated lands are provided with water by pumping stations. The main water sources are the transboundary rivers, the Amu Darya, and the Syr Darya, which transport a large amount of bedload and suspended sediments. In these water sources, the average annual turbidity is up to $5-7 \mathrm{~kg} / \mathrm{m} 3$, and the average monthly turbidity reaches $10-12$ $\mathrm{kg} / \mathrm{m} 3$. The content of abrasive particles with the Mohs hardness of 5 and more reaches $50-60 \%$ of the total amount of suspension. When these sediments pass through the pumping units, their hydro-abrasive wear is observed; this leads to a change in the main parameters of the pumps. Bedload sediments with the size of more than $1 \mathrm{~mm}$ cause the most intensive pumps hydro-abrasive wear. Therefore, in our research, much attention was paid to developing methods to prevent the ingress of bedload sediments into the flow part of pumping units. For this purpose, based on laboratory tests, taking into account the heterogeneity of bottom sediments, the dependence for determining the ridge forms' height was revealed. On the basis of this dependence was developed methods for determining the height of the threshold damless intakes and the height of the inlet of the suction pipe pumping unit relative to the riverbed bottom. The developed methods reduce abrasive wear of pumping units and increase their repair period.
\end{abstract}

\section{Introduction}

About $80 \%$ of water used annually in Uzbekistan is supplied by transboundary rivers, the Amu Darya and the Syr Darya, which usually transport a huge amount of bedload and suspended sediments. In these water sources, the average annual turbidity is up to 5-7 $\mathrm{kg} / \mathrm{m}^{3}$, and the average monthly turbidity reaches $10-12 \mathrm{~kg} / \mathrm{m}^{3}$. Most of these suspended sediments are smaller than $0.25 \mathrm{~mm}$, of which $40-60 \%$ are sediments smaller than $0.01 \mathrm{~mm}$. According to observations [1] at water intake to pumping stations from the Amu Darya river within the Surkhandarya region, the maximum content of suspended particles in water in April reaches $16.88 \mathrm{~kg} / \mathrm{m}^{3}$. The content of abrasive particles (with a Mohs hardness of 5 or more) reaches $50-60 \%$ of the total amount of suspension. According to generally

\footnotetext{
*Corresponding author: $\underline{\text { ikramov-1978@mail.ru }}$
} 
accepted technical standards, sedimentation in sedimentation tanks is carried out within only half of the total amount, and the rest must be transported through the irrigation network. In addition, numerous laboratory and field studies have proved that in addition to suspended sediments, bedload sediments in the bedload ridges form move at the bottom of these alluvial channels, in an amount of up to $20 \%$ of the suspended sediment consumption [2-5].

Currently, more than $50 \%$ of the irrigated land in Uzbekistan is provided with water by 1.693 pumping stations, which are on the balance sheet of the Water Resources Ministry of the Republic of Uzbekistan. The most intense abrasive wear of pumps is observed at those pumping stations that take water directly from rivers or at the initial sections of main channels. The main reason is the ingress of a large amount of suspended sediment and bottom particles with a size of more than $1 \mathrm{~mm}$ into the pump's inner part. As a result, there is intense hydro-abrasive wear of the flow part and the pump's impeller. This leads to an intensive reduction in the main parameters of the pumps and reduces their inter-repair period [6-12]. Since the centrifugal and axial pumps used at these pumping stations, according to the recommendations of the manufacturers, do not take into account the specific requirements of irrigation pumping stations, and they justify this by the fact that their pumps are designed for pumping clean water [13].

It follows that one of the factors determining the pumping unit's wear rate is the presence of solid abrasive particles in the pumped water.

\section{Materials and Methods}

The purpose of our research was to develop methods to prevent bedload sediment from entering the pumping unit flow part. For this, it was previously necessary to determine the bedload ridges height with different granulometric compositions of sediments. Based on the obtained dependence, methods are developed to determine the threshold height of a damless water intake structure and the height installation of the suction pipe inlet of the pumping unit relative to the channel bottom.

For this purpose, the following research tasks are defined:

1. Determination of the influence of the average size, sediment composition, and hydraulic characteristics of the flow on the ridge height:

$$
h_{\mathrm{\Gamma}}=f\left(H, \vartheta, Q, I, \vartheta / \vartheta_{0}, d_{c p s}, d_{\max }, d_{c p s} / d_{i}\right)
$$

here: $d_{c p s}$ is sediment mean diameter; $d_{\max }$ is maximal sediment diameter; $d_{i}$ is particle sizes with the corresponding percentage of security $(i=5,10,15,25,35,50,60,65,70,75,85$, $90,95) ; \vartheta$ and $\vartheta_{0}$ is average and non-eroding flow velocity; $H$ is average flow depth; $I$ is free water surface slope; $h_{\mathrm{r}}$ is ridge height.

2. Improvement of the method for determining the threshold height of the damless water intake structure.

3. Improvement of the method for determining the height installation of the suction pipe inlet of the pumping unit relative to the channel bottom.

\section{Results and Discussions}

To reduce hydro-abrasive wear of pumping units, it is necessary to prevent the ingress of bedload sediments into their flow part and pipelines. Bedload sediments could enter the pumping unit interior by direct water intake from a source with the eroded channel or by passing bedload sediments through the water intake structures thresholds into the supply channels of pumping stations. In both cases, to solve this problem, it is necessary to 
consider the bedload ridge's height. Therefore, this problem solution will be carried out in the following sequence:

1. Determination of the bed ridge forms height.

2. Determination of the threshold height of the damless water intake structure.

3. Determination of the height installation of the pumping unit's suction pipe inlet relative to the channel bottom.

\subsection{Determination of the bed ridge forms height}

Due to the difficulty of assessing the effect of heterogeneity of different types of natural sediments on the formation and movement of bedload ridges in natural conditions, main experiments were performed in the laboratory on the hydraulic tray [14].

Artificially made mixtures of 6 different types (edge fractioned, small fractioned, large fractioned, evenly fractioned, mean fractioned, and homogeneous) with the same mean diameters were used as a test material. The bedload sediments of the Chirchik River in the foothill section of the Gazalkent dam were used as the main experimental material. The types and varieties of prepared sediments correspond to the generally accepted classification.

The experimental studies included six series of basic experiments. Each series included from 10 to 15 experiments with water consumption $Q=5,10,15,201 / \mathrm{s}$. Only the amount of the supplied solid consumption changed (from 1 to 6 experiments were conducted). The total amount of made experiments were 81 experiments.

To establish the relationship between the ridge height and the different sediments composition with the constant mean particle size and relative flow rate, based on the obtained experimental data, graphical dependencies were constructed in the form $h_{r} / d=f\left(\vartheta / \vartheta_{0}\right)$ (figure 1).

Data analysis of the influence of particle size of sediment on the ridges height, depending on $\vartheta / \vartheta_{0} h_{r}=f\left(d, \vartheta / \vartheta_{0}\right)$ show fine fraction material $\left(\mathrm{d}_{\mathrm{i}}=0,1 \div 10,0 \mathrm{~mm} ; \mathrm{d}_{\mathrm{ax}}=2,51 \mathrm{~mm}\right)$ to experimental data with large fractional material $\left(\mathrm{d}_{\mathrm{i}}=0,1 \div 5,0 \mathrm{~mm}, \mathrm{~d}_{\mathrm{av}}=2.53 \mathrm{~mm}\right)$, ridges height with equal values $-9 / \vartheta_{0}$, tends to decrease. With increasing flow rate, the influence of particle size on the ridges height increases. If $9 / \vartheta_{0}=2.2 \div 2.4$ ridges have maximum height. With a further increase in the velocity ratio $\left(\$ / \vartheta_{0}>2,4\right)$ ridge height decreases [15]. At the same time, the influence of sediment size also decreases. At values $\vartheta_{/}=2.3 \div 2.5$ the influence of sediment size on the ridges height is insignificant. 


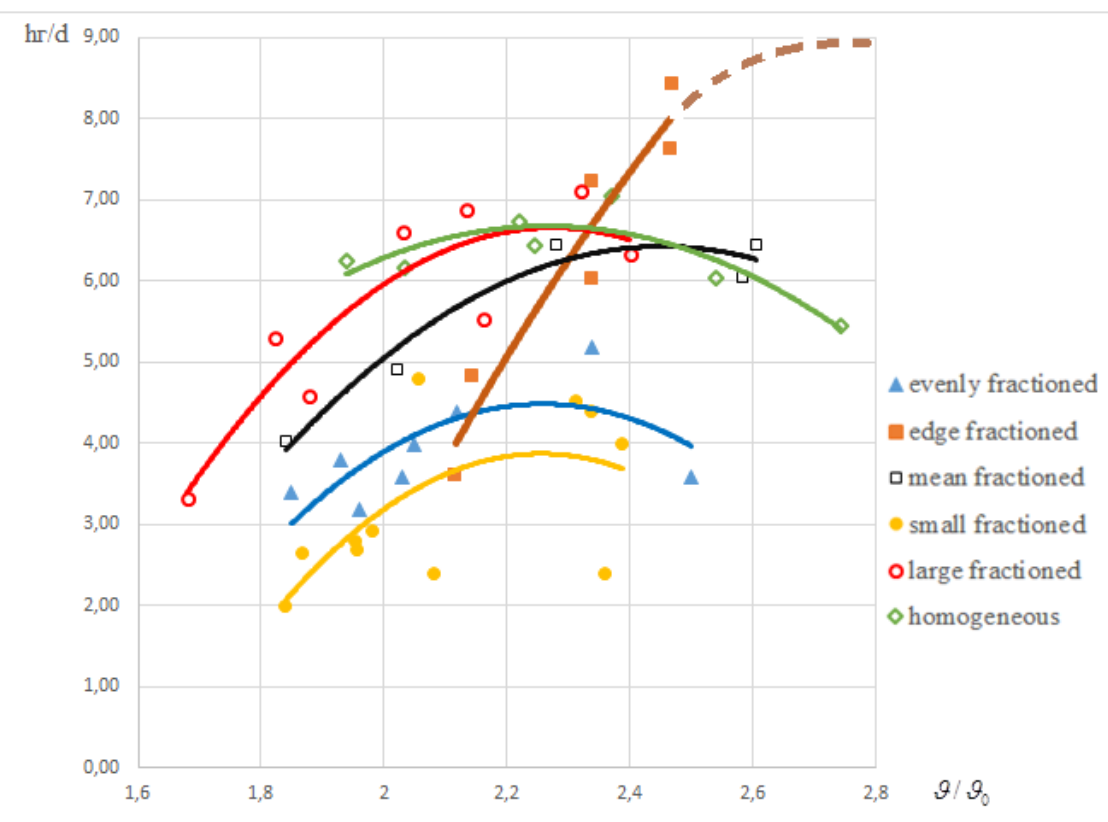

Fig. 1. Plot of ridge height and sediment composition to the relative flow velocity

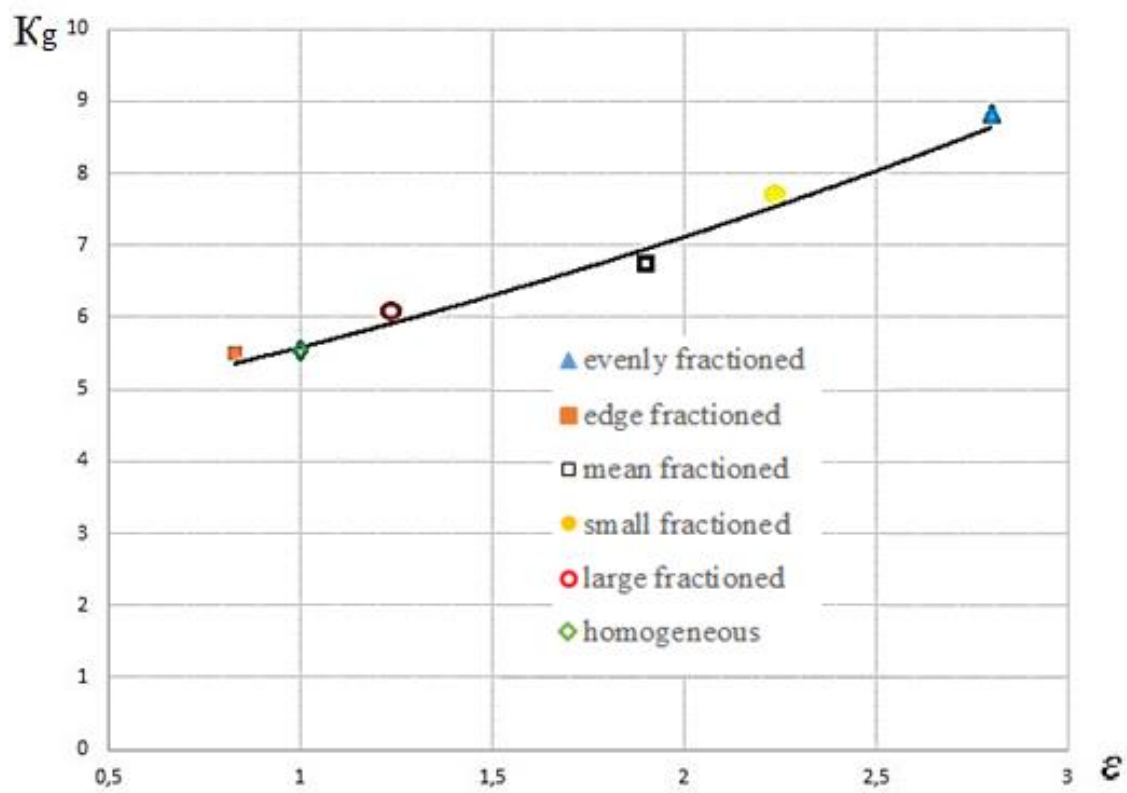

Fig. 2. Dependence graph of the coefficient $K_{g}$ on the sediment heterogeneity 


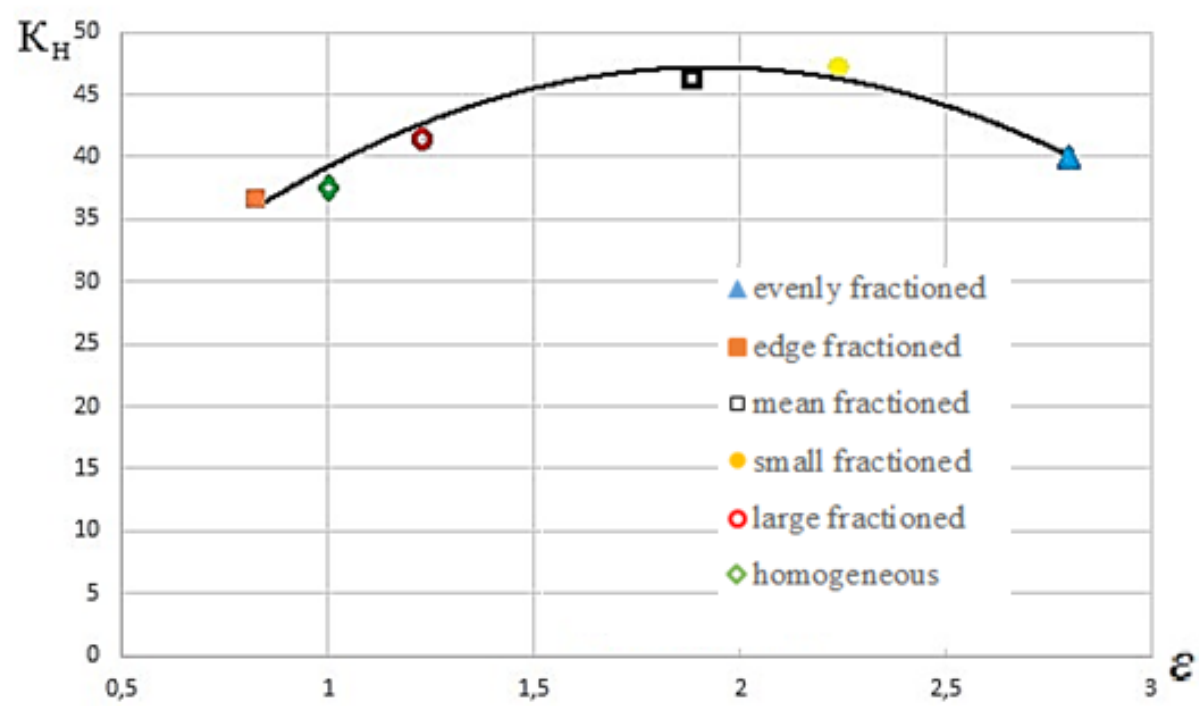

Fig. 3. Dependence graph of the coefficient $K_{n}$ on the sediment heterogeneity

The following design formula was obtained based on the graphical relationship analysis with an accuracy of $0.7 \div 0.9[14,15]$ :

$$
\frac{h_{r}}{d}=-K_{g} \cdot\left(\frac{\vartheta}{\vartheta_{0}}\right)^{2}+K_{n} \cdot\left(\frac{\vartheta}{\vartheta_{0}}-1.1\right)
$$

here: $\mathrm{K}_{\mathrm{g}}$ is the proportionality factor for the $i$-th composition, which, based on the graphical dependence obtained (figure 2), is determined by the following formula:

$$
K_{g}=4.38 \cdot e^{0.23 \cdot \varepsilon}
$$

$K_{\mathrm{H}}$ is the coefficient depending on the ridge heterogeneity, based on the resulting graphical dependence (figure 3), is determined by the formula:

$$
K_{n}=-9.2 \varepsilon^{2}+35.8 \varepsilon+12.7
$$

Substituting (2), (3) in (1) we get the following formula:

$$
\frac{h_{r}}{d}=-4.38 \cdot e^{0,23 \cdot \varepsilon} \cdot\left(\frac{\vartheta}{\vartheta_{0}}\right)^{2}-\left(9.2 \varepsilon^{2}-35.8 \varepsilon-12.7\right) \cdot\left(\frac{\vartheta}{\vartheta_{0}}-1.1\right)
$$

or:

$$
h_{\mathrm{r}}=d\left(-4.38 \cdot e^{0.23 \cdot \varepsilon} \cdot\left(\frac{\vartheta}{\vartheta_{0}}\right)^{2}-\left(9.2 \varepsilon^{2}-35.8 \varepsilon-12.7\right) \cdot\left(\frac{\vartheta}{\vartheta_{0}}-1.1\right)\right)
$$

When conducting experiments on the experimental tray, a change in the size of its height was observed in the form of a ridge pulsation (figure 4). When the dynamic balance is reached, the ridge height begins to grow, and when a certain height is reached, at the maximum average velocity, it is quickly washed away (within 45-60 seconds) and takes on an average size. After a certain time, the process is repeated again. This phenomenon has also been observed in field studies on natural watercourses. Therefore, the final ridge height should be taken equal to:

$$
h_{r}^{\prime}=h_{r}+\Delta h_{r}
$$


here: $h_{r}^{\prime}$ is calculated ridge height, $\mathrm{m}$;

$h_{r}$ is the average ridge height, determined by the formula (5);

${ }_{\Delta} h_{r}$ is pulsation value of the ridge height, $\mathrm{m}$.

The pulsation value of the ridge height depends on the types and sizes of sediments, the ridge form and varies within ${ }_{\Delta} h_{r}=(1.03 \div 1.15) h_{r}$.

Measurements and calculations allowed us to establish the following values of the ridge height ripple ${ }_{\Delta} h_{r}$ depending on the ridges shape: scaly-three-dimensional $-1.03 h_{r}$; riffles $1.05 h_{r}$; flat $-1.08 h_{r}$, flat-skewed $-1.1 h_{r}$; ribbon-chess $-1.12 h_{r}$; antidune-1.15 $h_{r}$.

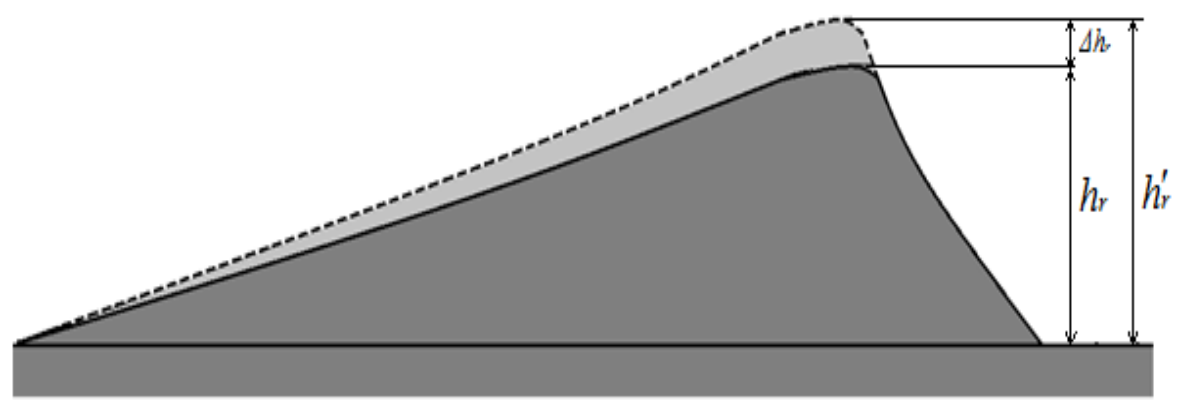

Fig. 4. Calculation scheme for determining the estimated ridge height

\subsection{Determination of the threshold height of the damless water intake structure}

The analysis of works $[2,16,17]$ devoted to damless water intake structures showed that the height of the bedload sediment ridges was not considered when determining the height of the water intake threshold. In these works, it is emphasized that the threshold of the water intake structure serves to protect a channel from ingress of bedload sediments. There are given various schemes of water intake structures with thresholds; these height is indicated structurally. They indicate that the threshold's height is set depending on the size and amount of bedload sediment and often recommend choosing the threshold's height in front of the gateway of the following sizes:

- in the case of sand sediments $-\mathrm{H}_{\mathrm{th}}=1.5-2.0 \mathrm{~m}$;

- in the case of gravel-pebble sediments $-\mathrm{H}_{\mathrm{th}}=1.0-1.5 \mathrm{~m}$.

As you see, the sediments smaller, the threshold should be higher. But they don't consider the ridge formations height when setting the threshold height, and the threshold height takes relatively to smooth bottom surface. Some works [18-20] recommend setting bottom circulation thresholds to reduce bedload sediments ingress into the channels. But even with their optimal installation angle $\left(\beta=45^{\circ}\right)$, channels cannot be completely protected from bedload sediments. Long-term observations of the water intake structures maintenance show that when setting the threshold's height, it is necessary to consider the bedload ridges height. This proposed the method for determining the threshold height of the damless water intake structure based on the obtained dependence (figure 5). 


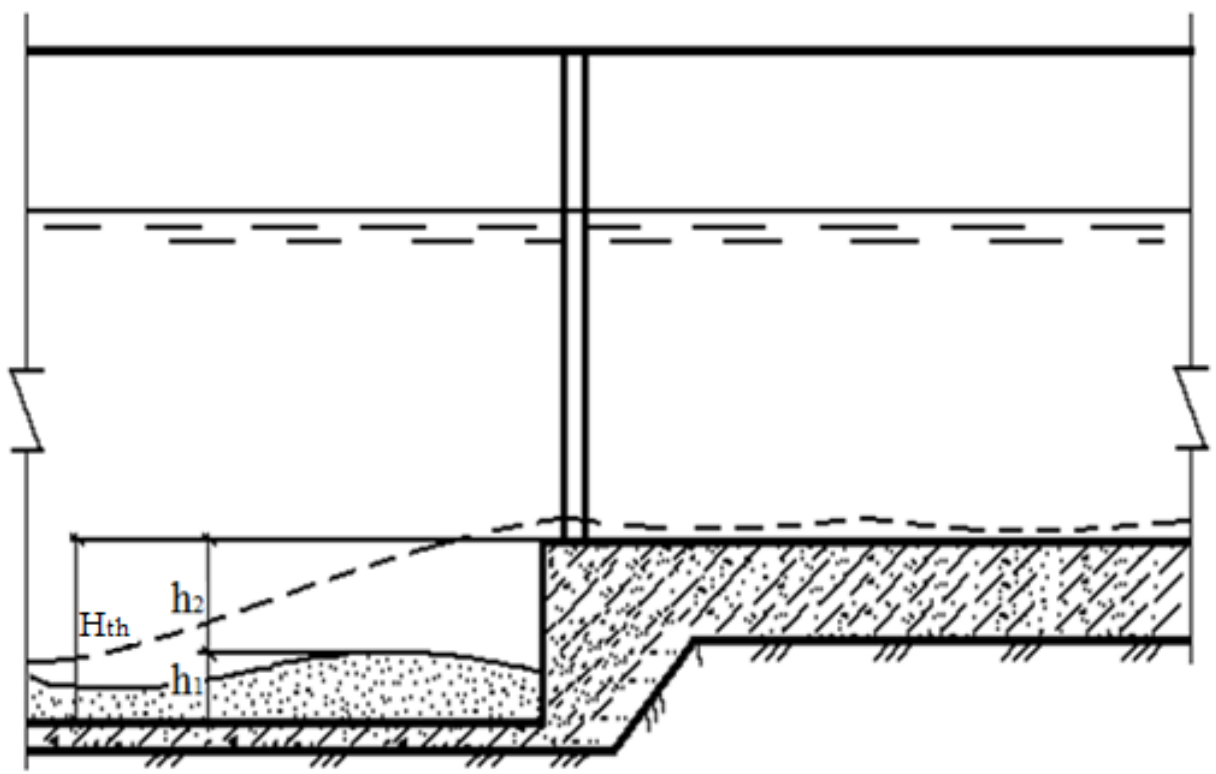

Fig. 5. Scheme for determining the threshold height taking into account the bedload ridges

According to the proposed method, it is recommended to determine the threshold height with the ridge bottom using the following formula:

$$
\mathrm{H}_{\mathrm{th}}=\mathrm{h}_{1}+\mathrm{h}_{2}
$$

here: $\mathrm{h}_{1}=h_{r}^{\prime}$ is bedload ridges height, determined by the formula (6); $\mathrm{h}_{2}$ - extra height stock, $\mathrm{h}_{2}=0.2 \cdot \mathrm{h}_{1}$.

Application of the recommended methods will lead to optimization of capital costs on the construction of the water intake structure threshold, reduce siltation of irrigation and supply canals of pumping stations, and reduce hydro-abrasive wear of the pumping units.

3.3 Determination of the height installation of the pumping unit's suction pipe inlet relative to the channel bottom

A literature review on determining the height installation of the pumping unit's suction pipe inlet $\mathrm{h}_{1}$ relative to the channel bottom (figure 6) showed that it is taken differently. But none of the literature does not indicate the calculation formula by its definition. All dependencies for determining the height installation $h_{1}$ are determined based on the diameter of the suction pipe's inlet $\mathrm{D}_{\text {in }}$. For example, based on [21], the minimum value of the inlet height is $\mathrm{h}_{1}=0.4 \mathrm{D}_{\text {in }}$, and according to the recommendations of most authors [2224], it is accepted $h_{1}=(0.5 \div 0.8) D_{\text {in. }}$. All operating pumping stations were designed and built based on this data, which is still ongoing. Also, no work on this topic considers the movement of bedload sediments in water sources with eroding channel, i.e., when water is taken directly from the river or large channels [25-28]. 


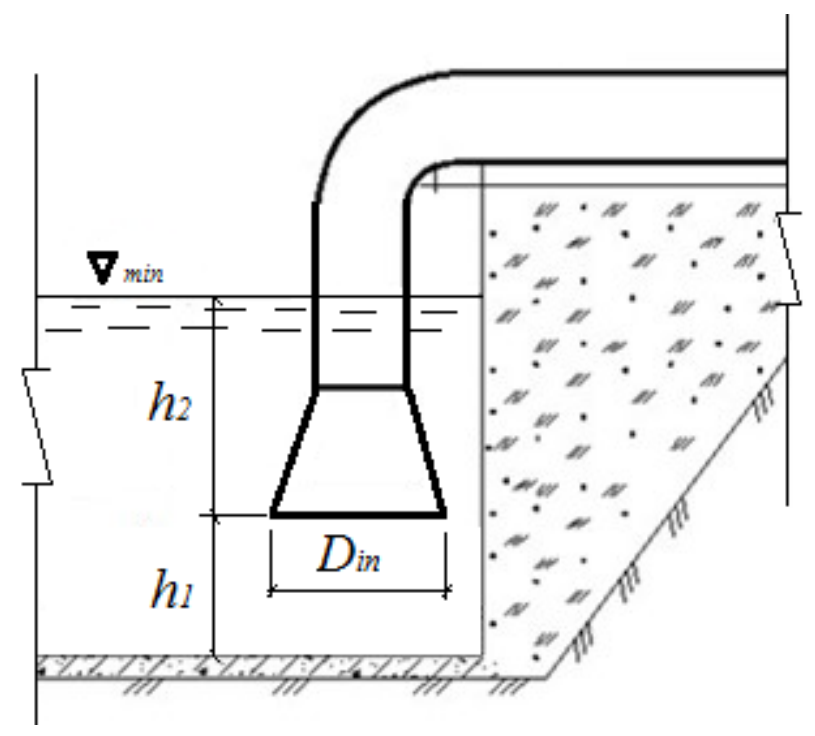

Fig. 6. Existing scheme for determination of the height installation of the pumping unit's suction pipe inlet relative to the channel bottom

Some authors in their works point out the need to take into account the water turbidity when determining $h_{1}$. Based on laboratory and field tests, the author [1] indicates that it is more appropriate to take $h_{1}=0.5 D_{\text {in }}$ for clean water intake, and for turbid water he recommends taking $\mathrm{h}_{1}=(0.9 \div 1) \mathrm{D}_{\text {in }}$. Assuming that he experimented for the water intake chamber pumping station, where he took into account the need not to siltation of the pumping chamber when the case of the water intake pumps water directly from the river or large canal where observing strongly expressed sediment ridge's movement, accounting of the sediment's ridge height when determining the height installation of the pumping unit's suction pipe inlet is an important need to protect pumping equipment and pipelines from hydro-abrasive wear.

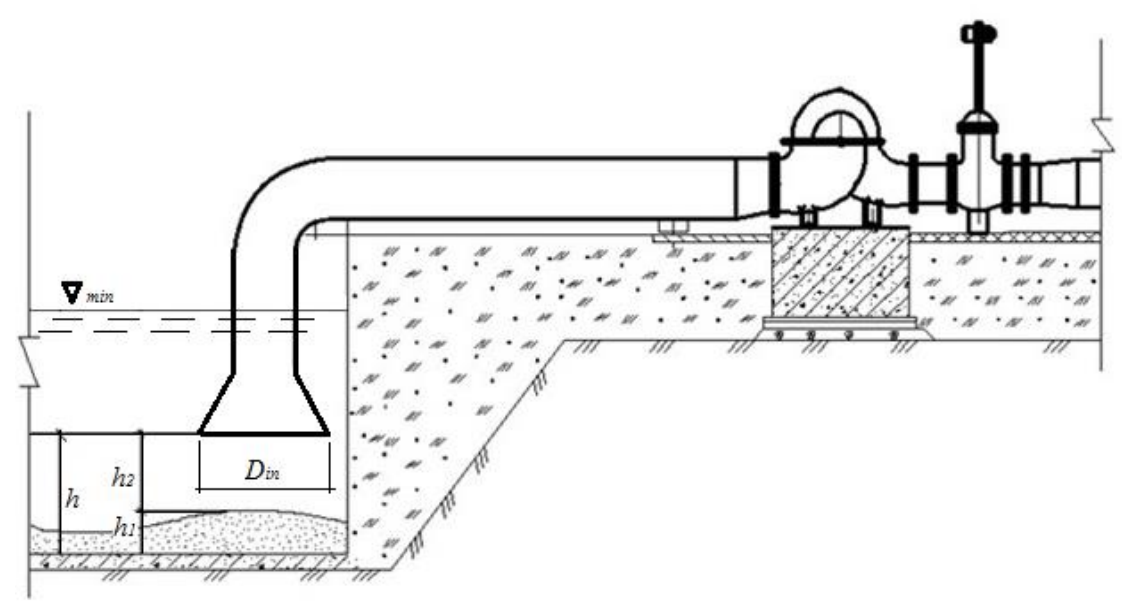

Fig. 7. The proposed scheme for determining of the height installation of the pumping unit's suction pipe inlet relative to the channel bottom 
After analyzing all works performed to solve this problem, we recommend taking the height installation of the pumping unit's suction pipe inlet relative to the channel bottom equal to (figure 7):

$$
h=h_{r}^{\prime}+0,5 D_{\text {in }}
$$

here: $h_{1}=h_{r}^{\prime}$ is bedload ridges height, determined by the formula (6); $\mathrm{h}_{2}$ is value equal to $0.5 D_{\text {in }} ; D_{\text {in }}$ is diameter of the suction pipe inlet.

\section{Conclusions}

1. based on experimental studies conducted with various compositions but the same mean sediment diameters, obtained the dependence for determining the bedload sediment's ridge height.

2. On the basis of accounting the bedload ridge's height developed methods for determining the damless intakes threshold height and the height installation of the pumping unit's suction pipe inlet relative to the channel bottom with water intake directly from the river or large channels.

3. Using the recommended methods gives the possibility of optimizing the threshold height of the damless intakes structures of the pumping station's supply channels and the height installation of the pumping unit's suction pipe inlet relative to the channel bottom that prevents sediment in flowing part of pumps and their pipelines.

4. Avoiding the bedload sediment ingress into the inner part of irrigation pumping units will significantly reduce their hydro-abrasive wear intensity that increase the inter-repair period, and therefore the overall service life. Also, a reduction in the ingress of bedload sediment into the supply channels will reduce the operating costs of channels cleaning from sediments.

\section{References}

1. Mamajonov, M. Improving the efficiency of operation of centrifugal and axial pumps pumping stations irrigation systems. Doctor of Science Dissertation. (2005).

2. Curran, J. C., Waters, K. A. \& Cannatelli, K. M. Real time measurements of sediment transport and bed morphology during channel altering flow and sediment transport events. Geomorphology 244, (2015).

3. Guo, Q., Zheng, Z., Huang, L. \& Deng, A. Regularity of sediment transport and sedimentation during floods in the lower Yellow River, China. Int. J. Sediment Res. 35, (2020).

4. Bi, S., Liu, M., Xu, M. \& Long, X. Analysis on the flow field of inlet structure of Xingshipo pumping station by CFD mehtod. in IET Conference Publications vol. 2014 (Institution of Engineering and Technology, 2014).

5. Shaazizov, F. Studies of turbulent flow characteristics of dividing open water streams. IOP Conf. Ser. Mater. Sci. Eng. 1030, (2021).

6. Mamajanov, M. et al. Vane pumps with cavitation-abrasive wear of their parts. IOP Conf. Ser. Mater. Sci. Eng. 883, 012002 (2020).

7. Horszczaruk, E. K. Hydro-abrasive erosion of high performance fiber-reinforced concrete. Wear 267, 110-115 (2009).

8. Sharma, S. \& Gandhi, B. K. Erosion Wear Behavior of Martensitic Stainless Steel Under the Hydro-Abrasive Condition of Hydropower Plants. J. Mater. Eng. Perform. 29, 7544-7554 (2020).

9. Engel, R., Fibier, A., Heldt, J. \& Ronecker, A. Hydro-Abrasive wear damage at 
reactor recirculation pump bearing journals. in American Society of Mechanical Engineers, Pressure Vessels and Piping Division (Publication) PVP vol. 7 137-144 (2012).

10. Yigit, K. \& Aydin, H. Hydro-abrasive erosion resistance of C45 steel in different heattreated states on a designed wear test apparatus. Mater. Test. 52, 323-331 (2010).

11. Glovatsky, O., Ergashev, R., Saparov, A., Berdiev, M. \& Shodiev, B. Cavitationabrasive wear working collectors of pumps. in IOP Conference Series: Materials Science and Engineering vol. 869 (2020).

12. Mamajonov, M., Bazarov, D. R., Uralov, B. R., Djumabaeva, G. U. \& Rahmatov, N. The impact of hydro-wear parts of pumps for operational efficiency of the pumping station. in Journal of Physics: Conference Series vol. 1425 (Institute of Physics Publishing, 2020).

13. Al., K. V. K. et. Pump engineering problems and their solutions. (1989).

14. Ikramov, N. \& Majidov, T. Experimental Research of the Influence of Bedload Sediment Heterogeneity on Length, Height and Shifting Velocity of Growing Bed Configuration. Ind. Eng. 4, 43-49 (2020).

15. Ikramov, N., Majidov, T., Kan, E. \& Ikromov, I. The height of a damless water intake structure threshold. in IOP Conference Series: Materials Science and Engineering vol. 869072009 (Institute of Physics Publishing, 2020).

16. Rasskazov L.N., E. Hydrotechnical constructions (on rivers). (Associations of construction universities, 2011).

17. Nesterov, M. V. Hydrotechnical constructions. (Infra-M, 2015).

18. Klovsky A.V., Rumyantsev I.S., K. D. . Some ways to improve the hydraulic working conditions of damless intake waterworks with bottom circulation thresholds. Environ. Manage. 3, 45-52 (2015).

19. Bazarov, D., Markova, I., Norkulov, B., Isabaev, K. \& Sapaeva, M. Operational efficiency of water damless intake. in IOP Conference Series: Materials Science and Engineering vol. 869 (Institute of Physics Publishing, 2020).

20. Bazarov, D. The effects of morphometric elements of the channel on hydraulic resistance of machine channels of pumping stations. in IOP Conference Series: Materials Science and Engineering vol. 869 (Institute of Physics Publishing, 2020).

21. Departmental building codes (VSN) 33-2.2.12-87 «Reclamation systems and structures. Pumping plant. Design standards». (1987).

22. Jones, G. M., Sanks, R. L., Tchobanoglous, G. \& Bosserman, B. E. Pumping Station Design. Pumping Station Design (Elsevier Ltd, 2008). doi:10.1016/B978-1-85617513-5.X5001-X.

23. Lobanoff, V. S. \& Ross, R. R. Centrifugal Pumps: Design and Application. Centrifugal Pumps: Design and Application (Elsevier Inc., 2013). doi:10.1016/C20090-26797-3.

24. Gülich, J. F. Centrifugal pumps. Centrifugal Pumps vol. 9783642401145 (SpringerVerlag Berlin Heidelberg, 2014).

25. Robert L. Sanks, George Tchobanoglous, B. E. Pumping station design. (Elsevier Ltd, 2008).

26. Ikramov, N., Majidov, T., Kan, E. \& Akhunov, D. The height of the pumping unit suction pipe inlet relative to the riverbed bottom. IOP Conf. Ser. Mater. Sci. Eng. 1030, 012125 (2021).

27. Bazarov D., Vatin N., Obidov B., and Vokhidov O. Hydrodynamic effects of the flow on the slab of the stand in the presence of cavitation. IOP Conf. Ser. Mater. Sci. Eng. 1030, 012110 (2021).

28. Bazarov D. and Vokhidov O. Extinguishing Excess Flow Energy in Spillway Structures. In book: Proceedings of EECE 2020, LNCE 150, pp. 535-545, (2021) 
DOI: 10.1007/978-3-030-72404-7_52 